\title{
Genomic association study for age at first calving and calving interval in Romosinuano and Costeño con Cuernos cattle
}

\author{
J.C. Fernández ${ }^{1}$, J.E. Pérez ${ }^{1}$, N. Herrera ${ }^{1}$, R. Martínez $^{2}$, D. Bejarano ${ }^{2}$ \\ and J.F. Rocha ${ }^{2}$ \\ ${ }^{1}$ Corporación Colombiana de Investigación Agropecuaria, Centro de \\ investigación Turipaná, Córdoba, Colombia \\ ${ }^{2}$ Corporación Colombiana de Investigación Agropecuaria, Centro de \\ investigación Tibaitatá, Cundinamarca, Colombia
}

Corresponding author: J.F. Rocha

E-mail: jfmartinez@agrosavia.co

Genet. Mol. Res. 18 (2): gmr18258

Received February 14, 2018

Accepted April 15, 2019

Published May 03, 2019

DOI http://dx.doi.org/10.4238/gmr18258

\begin{abstract}
Inheritance of fertility traits in cattle is complex since they are controlled by multiple loci. Genome-wide association studies are an efficient tool to detect genomic regions that explain the phenotypic variation for a trait of interest. The aim of this study was to identify genomic regions that affect the age at first calving (AFC) and the calving interval (CI) in the Romosinuano (ROMO) and Costeño con Cuernos (CCC) creole cattle breeds and nominate candidate genes that influence these reproductive traits. AFC and CI records were obtained from 4,063 ROMO and 3,922 CCC, and a total of 962 animals were genotyped using the BovineSNP50. Based on the single-step GBLUP methodology, the effects of 54K single nucleotide polymorphisms (SNPs) were grouped within windows of eight adjacent SNPs to explain the genetic variance. Sixty-six SNP windows were significantly associated with AFC (31 regions) and CI (35 regions). Of these regions, 17 were associated with $\mathrm{AFC}$ in ROMO, 14 with $\mathrm{AFC}$ in CCC, 17 with $\mathrm{CI}$ in ROMO and 18 with $\mathrm{CI}$ in CCC. From these, nine candidate genes (CACNA1A, CACNA1D, CACTIN, IARS2, PGRMC2, PTGDR, SYT10, UBE4A, RNF17) were identified as possible candidates involved in molecular mechanism that affect physiological mechanisms, such as hormonal regulation, ovarian cyclicity, growth rate, gametogenesis, acceleration of puberty, regulation
\end{abstract}


of immune system, early embryonic development and the pathways to embryo-maternal recognition and maintenance of pregnancy. Furthermore, some genomic regions located in BTA1, BTA5 and BTA14 showed a pleiotropic effect on both AFC and CI. The polymorphisms identified in this study can help determine gene networks involved in the physiology of reproduction in cattle and to explain the inherent genetic variance of traits that measure reproductive performance in cattle. Some of these polymorphisms might be considered for breeding selection strategies to improve complex traits such as AFC and CI in beef and dairy cattle production systems.

Key words: Age at first calving; Calving interval; Romosinuano; Costeño con Cuernos; Fertility; GWAS

\section{INTRODUCTION}

Romosinuano (ROMO) and Costeño Con Cuernos (CCC) are two Colombian cattle breeds that are well adapted to the climatic conditions of the Caribbean region of Colombia and are characterized by having a high reproductive efficiency (Martínez et al., 2009). A poor reproductive performance is one of the main causes of early culling of cows on livestock farms. Therefore, the fertility of creole cattle breeds is an important feature that should be considered in breeding programs, to ensure that the selection applied to other productive traits does not affect the reproductive efficiency that characterizes these breeds. The reproductive characteristics that are most frequently used to evaluate the fertility of beef cows in Colombia are the age at first calving (AFC) and the calving interval (CI). These are traits that are easily measured and are part of genetic evaluations due to its direct influence on the herd productivity (Rocha et al., 2012). Average AFC and CI values of 422-441 days and 37 months, respectively, have been reported in CCC and ROMO cattle breeds (Ossa et al., 2011; Ossa et al., 2013).

$\mathrm{AFC}$ and $\mathrm{CI}$ are polygenic traits controlled by many genes, each with a small effect on phenotypic variation, and their expression depends to a large extent on environmental factors (Snelling et al., 2013). The characterization of the chromosomal regions that affect $\mathrm{AFC}$ and $\mathrm{CI}$ in the ROMO and $\mathrm{CCC}$ cattle contributes to the genetic improvement efforts by identifying candidate genes that play a part in understanding much better their reproductive physiology. Currently, advances in DNA sequencing technologies have allowed the identification of many genetic variants in the Bos taurus genome, mainly, simple nucleotide polymorphisms (SNPs) (Bovine HapMap Consortium, 2009). The development of efficient methods for genotyping thousands of SNPs such as high density microarrays (Matukumalli et al., 2009), together with the development of statistical methods required for their analysis (Nicolazzi et al., 2015), have led to the development of new methodologies for gene mapping, such as genomewide association studies (GWAS), which are based on the linkage disequilibrium between unknown functional mutations and genotypes of known SNPs distributed throughout the genome of animals (Rolf et al., 2010). 
The aim of this study was to identify genomic regions that affect the AFC and the $\mathrm{CI}$ in ROMO and $\mathrm{CCC}$ creole cattle breeds and use these regions to identify candidate genes that influence fertility in cattle.

\section{MATERIAL AND METHODS}

\section{Study location, animals and phenotypic data}

The data used for this study were the productive records of the creole breeds ROMO and CCC obtained from an in vivo animal germplasm bank kept in Turipaná research center of the Corporación Colombiana de Investigación Agropecuaria AGROSAVIA. This research center is located in the valley of the Sinú river in the municipality of Cereté, department of Córdoba, Colombia, at $8^{\circ} 31^{\prime} 16^{\prime \prime}$ of latitude $\mathrm{N}$ and $75^{\circ} 58^{\prime} 11^{\prime \prime}$ of longitude W. The area is in the Humid Forest climatological zone, with an average temperature of $27.5^{\circ} \mathrm{C}, 83 \%$ relative humidity and an annual precipitation of $1200 \mathrm{~mm}$, distributed in a low precipitation season from the months December to March and another period of high precipitation from April to November. This in vivo germplasm bank has the largest population of ROMO and CCC in Colombia, and moreover, since one of the main objectives of this bank is the conservation of the genetic variability in these breeds, it constitutes a representative sample of the whole population in the country.

Data included in this study was collected only from animals that had complete reproductive records, so that, animals with incomplete or misguided information were excluded. Records of AFC and CI were obtained from 4063 ROMO and 3922 CCC animals. Of these, $527 \mathrm{ROMO}$ and $435 \mathrm{CCC}$ with the highest information contribution for both breeds were genotyped using the BovineSNP50 bead chip of Illumina (54609 SNP).

\section{Quality control of genotypes and imputation}

The PLLNK program was used to calculate the frequency of the least common allele or minor allele frequency (MAF) in all the autosomal markers. Five categories were established to evaluate the distribution of allelic frequencies, which represent the proportion of SNPs with MAF values that are within the following ranges, $\geq 0.03$ to $<0.1, \geq 0.1$ to $<0.2, \geq 0.2$ to $<0.3, \geq 0.3$ to $<0.4$ and $\geq 0.4$ to $\leq 0.5$. The comparison between the two breeds (CCC and ROMO) was plotted using the R software.

The quality control of the SNP genotypes was independent for each breed, following the rules described by Wiggans et al. (2010) using the PLINK v1.9 software (http://pngu.mgh.harvard.edu/purcell/ plink) (Purcell et al., 2007). The SNPs excluded were those with a call rate lower than $90 \%$, or if they showed an extreme deviation from the Hardy-Weinberg equilibrium $(\mathrm{P}<0.01)$, for example, when SNPs in autosomal chromosomes of known composition show both homozygous genotypes but without heterozygous genotypes. Likewise, SNPs with unknown genomic position, or those located in sex chromosomes, were excluded. After quality control, monomorphic 
markers with MAF below 3\% were eliminated. Animals with a call rate lower than $90 \%$ or with inconsistencies in their pedigree were also eliminated. Finally, the control process included 42,123 effective polymorphic SNPs for the ROMO breed (77.13\%) and 42,125 effective polymorphic SNPs for the CCC breed (77.14\%).

An imputation process of the information of the highest density panel (50K) to the lowest density panel (7K) was carried out (Browning and Browning, 2011). All animals had genomic information for approximately 54,000 SNPs. The imputation of the panel genotypes from $7 \mathrm{~K}$ to $50 \mathrm{~K}$ was carried out using the FImpute program (Sargolzaei et al., 2014).

\section{Statistical analysis}

An association analysis was performed with the single-step genomic-wide association study (ssGWAS) methodology proposed by Wang et al. (2012) and based on a single-step BLUP method (ssBLUP) (Misztal et al., 2013). Under this methodology, the genomic breeding values (GEBV) are estimated using phenotypes, genotypes and pedigree, and simultaneously the allelic substitution effect and the variance explained by the markers included in the analysis. Unlike other analysis methods such as 2-step or Bayes, the ssGWAS uses all the available phenotypic information, the pedigree and the effect of the markers, allowing to include in the analysis information of genotyped and non-genotyped animals (Wang et al., 2012).

In the ssGWAS, the kinship matrix $\mathrm{A}^{-1}$ is replaced by an $\mathrm{H}^{-1}$ matrix that has the following structure (Aguilar et al., 2010):

$$
H^{-1}=A^{-1}+\left[\begin{array}{cc}
0 & 0 \\
0 G^{-1}-A_{22}^{-1}
\end{array}\right]
$$

where matrix $\mathrm{A}_{22}^{-1}$ is the numerator of the kinship matrix for genotyped animals, and $\mathrm{G}$ is a genomic relationships matrix, which can be created following the methodology described by VanRaden (2008).

To estimate the variance component, the AIREML module of the BLUPF90 program (Aguilar et al., 2010) was used through a model that included the fixed effects of year, season, herd, and covariate age of the cow during calving. For each characteristic under analysis, a different model was used, as described below:

$$
\begin{gathered}
Y \text { Age at first calving }=X B+Z a+e \\
Y \text { Calving interval }=X B+Z a+Z p e+e
\end{gathered}
$$

where $\mathrm{X}$ is the incidence matrix of fixed effects; $\mathrm{Z}$ is the incidence matrix of random effects; $B$ is the solutions vector for fixed effects; $a$ is the solutions vector by direct random effects; pe is the solutions vector for random effects of a permanent environment; and $\mathrm{e}$ is the variance of the error. 
The ability to differentiate between markers with large effects and those with small effects was improved using windows from 8 adjacent SNPs, and the variance explained by these windows was used to build Manhattan Plots. For the purpose of identifying quantitative trait locus (QTL) or genomic regions associated with reproductive traits, a threshold was defined according to the genetic variance explained by the windows of 8 adjacent SNPs, accepting as regions with significant effect those with values $\geq 0.13$.

\section{Candidate genes}

The regions of greatest interest were defined based on the results of the association analysis. The putative candidate genes located in or near these regions were investigated using the Bos taurus UMD3.1 bovine genome version (Zimin et al., 2009). The information of each gene was obtained from the Ensembl Database (ensembl.org): Ensembl Bos taurus 81.31, UMD3.1. The existence of QTLs associated with reproductive characteristics was verified with the Animal QTLdb database (2016).

The functional analysis of the mapped genes was carried out through the UniProt (2016) and GeneCards ${ }^{\circledR}$ (2016) websites, which were used to verify the functional information of the genes. When no information was available for Bos taurus genes, orthologous gene annotations were used in humans and mice to proceed with an in silico functional analysis, which allowed defining a list of genes located within or near the regions of interest.

\section{RESULTS}

The heritability $\left(h^{2}\right)$ for CI estimated from genomic information was 0.06 and 0.09 in ROMO and CCC, respectively. Higher $h^{2}$ values were obtained for AFC $(0.14$ and 0.16 in ROMO and CCC, respectively). The $h^{2}$ values, the genetic variance and residual variance are presented in Table 1.

Table 1. Variance components and heritability of age at first calving (AFC) and calving interval (CI) in Romosinuano (ROMO) and Costeño Con Cuernos (CCC) cattle breeds.

\begin{tabular}{lllll}
\hline Breed & Trait & Genetic variance & Residual variance & Heritability \\
\hline \multirow{2}{*}{ ROMO } & AFC & 3.6 & 24.9 & 0.14 \\
& CI & 926 & 16.805 & 0.06 \\
CCC & AFC & 6.5 & 39.4 & 0.16 \\
& CI & 1.526 .4 & 17.533 & 0.09 \\
\hline
\end{tabular}

This study allowed the identification of genomic regions associated with AFC and $\mathrm{CI}$, and the proportion of total additive genetic variance explained by these regions was estimated. Figures 1 to 4 show the Manhattan plots constructed from the proportion of genetic variance explained by windows of eight adjacent SNPs within the same chromosome, for the AFC and CI characteristics in the ROMO and CCC breeds. In these figures, the chromosomes are numbered and differentiated by color, and the 
individual points correspond to the SNPs in each chromosome with a spatial distribution dependent on the genetic variance explained by each window (Y-axis), and the position occupied by the SNP in pairs of bases (bp) inside each chromosome (Xaxis).

Figure 1 shows the Manhattan plot for CI in ROMO and CCC. Seventeen significant SNP windows associated with CI were identified in chromosomes BTA1, BTA2, BTA5, BTA10, BTA14, BTA15, BTA16, BTA17, BTA21, BTA24, and BTA29 in ROMO. The window that explained the highest proportion of genetic variance for $\mathrm{CI}$ $(0.59 \%)$ was located in BTA1, followed by the regions located in BTA3 $(0.39 \%)$ and BTA4 $(0.38 \%)$.

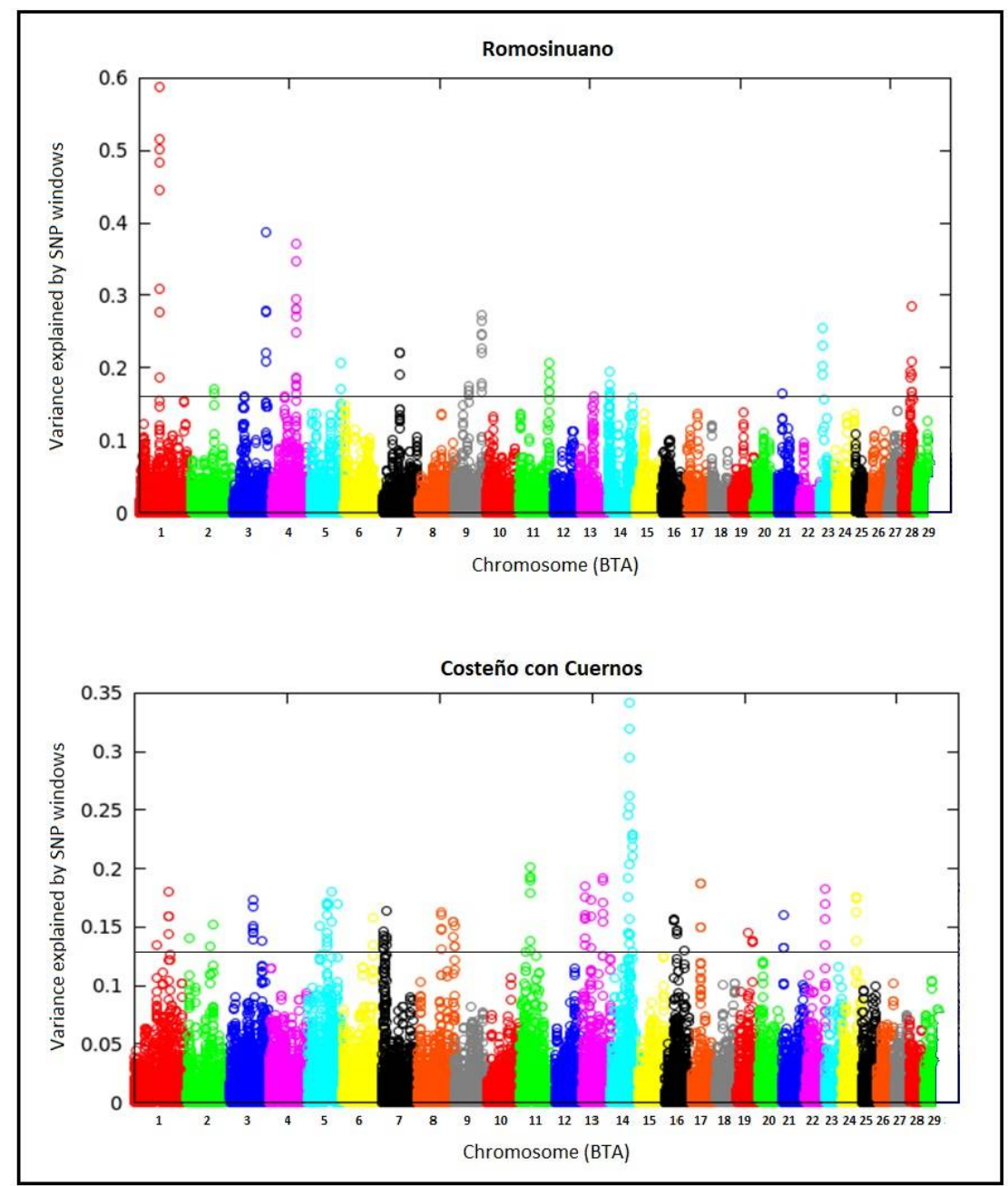

Figure 1. Manhattan plot for calving interval in Romosinuano and Costeño with Cuernos cattle. 
Several genes positioned nearby these regions (e.g. GPC5 on BTA1) are described in Table 2.

In CCC, 18 SNP windows associated with $\mathrm{CI}$ were found in BTA1, BTA3, BTA5, BTA7, BTA8, BTA11, BTA13, BTA14, BTA16, BTA17, BTA21, BTA22, and BTA24 (Figure 1). The window explaining the highest proportion of genetic variance $(0.34 \%)$ was located in BTA14 (Table 2). The following regions showing the highest explained variance were at BTA11 (0.21\%), BTA13 (0.19\%), BTA17 $(0.19 \%)$, and BTA22 $(0.18 \%)$. Genes of particular interest such as PGRMC2 (BTA17) were found in these genomic regions.

Table 2. Genomic position of the SNP-windows with a significant effect on calving interval in Romosinuano and Costeño con Cuernos cattle.

\begin{tabular}{|c|c|c|c|c|}
\hline Breed & BTA & $\begin{array}{l}\text { Genomic position } \\
\text { (Mb) }\end{array}$ & $\begin{array}{l}\text { Percentage of } \\
\text { genetic } \\
\text { variance } \\
\text { explained }\end{array}$ & $\begin{array}{l}\text { Genes located nearby to or within this genomic } \\
\text { region }\end{array}$ \\
\hline \multirow{17}{*}{ Romosinuano } & 1 & $66.48-66.63$ & 0.59 & GPC5, STXBP5L, POLQ \\
\hline & 3 & $106.39-106.61$ & 0.39 & COL9A2, ZMPSTE24, RLF \\
\hline & 3 & $109.46-109.54$ & 0.39 & - \\
\hline & 4 & $76.46-76.55$ & 0.38 & - \\
\hline & 4 & $78.77-78.88$ & 0.38 & MRPL32 \\
\hline & 4 & $44.88-44.97$ & 0.18 & RELN \\
\hline & 5 & $76.92-77.18$ & 0.13 & - \\
\hline & 7 & $56.65-57.01$ & 0.22 & - \\
\hline & 9 & $50.1-50.19$ & 0.19 & ASCC3, SIM1 \\
\hline & 9 & $92.43-92.52$ & 0.27 & CNKSR3 \\
\hline & 11 & $93.24-93.75$ & 0.21 & - \\
\hline & 14 & $6.08-6.67$ & 0.2 & - \\
\hline & 14 & $3.24-3.34$ & 0.19 & - \\
\hline & 14 & $77.1-77.17$ & 0.17 & MMP16 \\
\hline & 21 & $19.57-19.66$ & 0.18 & - \\
\hline & 23 & $14.22-14.34$ & 0.25 & LRFN2 \\
\hline & 28 & $29.55-29.85$ & 0.29 & ANXA7, MSS51, USP54, MYOZ1, FUT11 \\
\hline \multirow{18}{*}{$\begin{array}{l}\text { Costeño con } \\
\text { Cuernos }\end{array}$} & 1 & $106.64-106.88$ & 0.19 & - \\
\hline & 3 & $80.52-80.65$ & 0.17 & AK4 \\
\hline & 5 & $69.35-69.51$ & 0.18 & - \\
\hline & 7 & $5.8-5.9$ & 0.16 & MYO9B \\
\hline & 7 & $18.71-18.85$ & 0.16 & ADGRE1 \\
\hline & 8 & $72.8-72.95$ & 0.16 & - \\
\hline & 11 & $26.42-26.52$ & 0.21 & PPM1B \\
\hline & 13 & $64.92-65.01$ & 0.18 & TRPC4AP, EDEM2 \\
\hline & 13 & $28.66-28.78$ & 0.19 & FRMD4A \\
\hline & 14 & $65.1-65.19$ & 0.34 & - \\
\hline & 14 & $55.42-56.46$ & 0.25 & - \\
\hline & 16 & $30.11-30.19$ & 0.16 & PARP1 \\
\hline & 16 & $37.79-37.9$ & 0.13 & PGPEP1L \\
\hline & 17 & $30.48-30.68$ & 0.19 & - \\
\hline & 17 & $29.76-29.94$ & 0.19 & PGRMC2, COMMD \\
\hline & 21 & $8.23-8.31$ & 0.16 & IGF1R \\
\hline & 22 & $60.85-61.04$ & 0.18 & - \\
\hline & 24 & $45.9-46$ & 0.17 & SLC14A1 \\
\hline
\end{tabular}


In ROMO, a total of $17 \mathrm{SNP}$ windows that explained $0.13 \%$ of the genetic variance for $\mathrm{AFC}$ as a whole were identified in chromosomes BTA1, BTA2, BTA5, BTA10, BTA14, BTA15, BTA16, BTA17, BTA21, BTA22, BTA24, and BTA29 (Figure 2). The regions that accounted for the highest proportion of the genetic variance for this trait were located in BTA1 $(0.5 \%)$ and BTA10 $(0.55 \%)$. Several genes of interest such as IARS2 (BTA16), UBE4A (BTA15), CACNA1D (BTA22) and PTGDR (BTA10) were found within these genomic regions. In CCC, the SNP windows identified in BTA1 and BTA14 had a common significant effect on both AFC and CI. Similarly, this was also observed in ROMO, where the SNP windows located on BTA5 had a significant effect on both traits (Table 3).

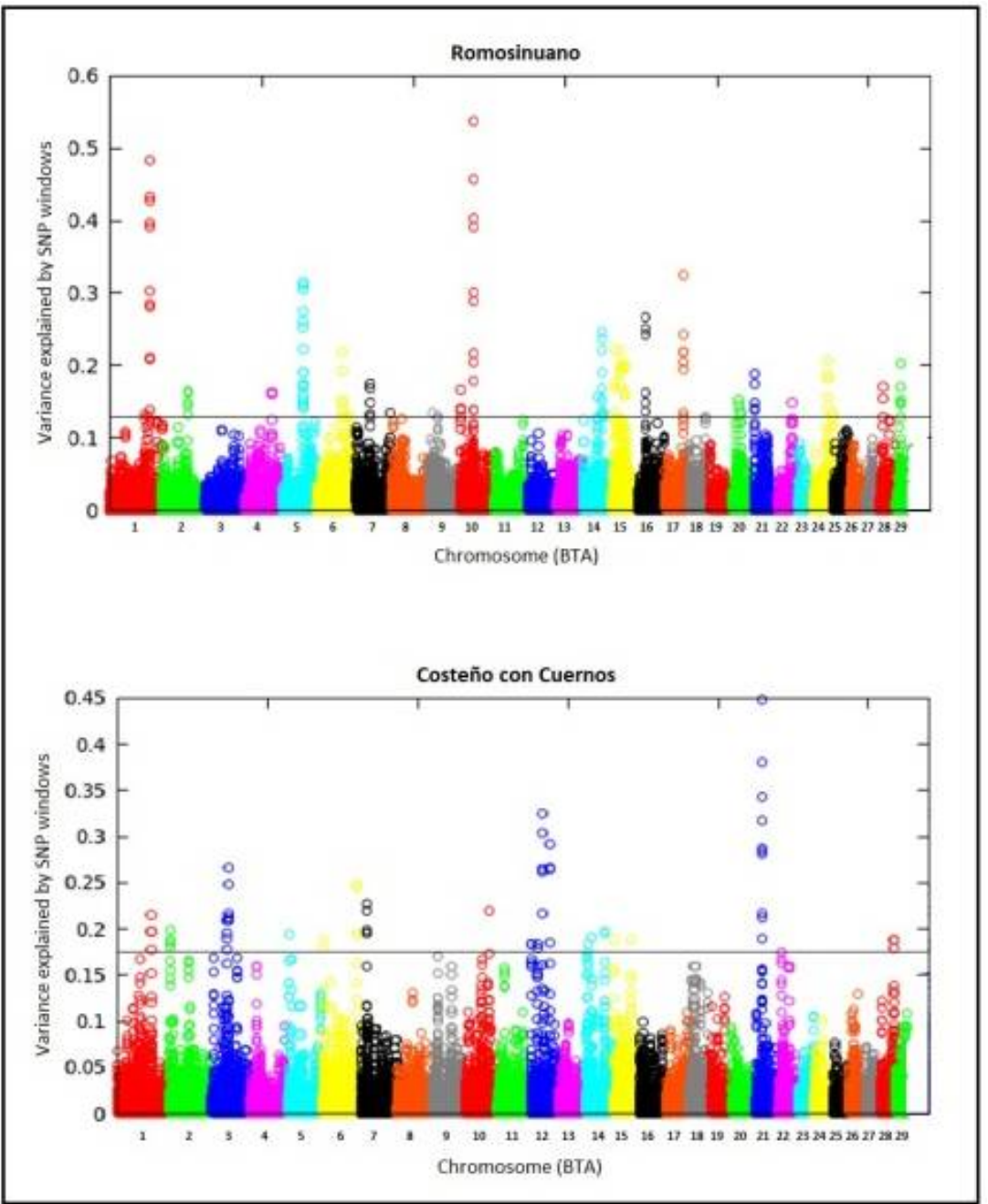

Figure 2. Manhattan plot for age at first calving in Romosinuano and Costeño with Cuernos cattle. 
Table 3. Genomic position of the SNP-windows with a significant effect on age at first calving in Romosinuano and Costeño con Cuernos cattle.

\begin{tabular}{|c|c|c|c|c|}
\hline Breed & BTA & $\begin{array}{l}\text { Genomic } \\
\text { position }(\mathrm{Mb})\end{array}$ & $\begin{array}{l}\text { Percentage of } \\
\text { genetic } \\
\text { variance } \\
\text { explained }\end{array}$ & $\begin{array}{l}\text { Genes located nearby to or within this genomic } \\
\text { region }\end{array}$ \\
\hline \multirow{17}{*}{ Romosinuano } & 1 & $127.46-127.55$ & 0.5 & - \\
\hline & 2 & $78.3-78.41$ & 0.18 & GYPC \\
\hline & 5 & $76.91-77.18$ & 0.31 & SYT10 \\
\hline & 9 & $32.39-32.48$ & 0.13 & FAM184A \\
\hline & 10 & $45.49-45.56$ & 0.55 & PTGDR, ZNF609 \\
\hline & 10 & $45.35-45.47$ & 0.55 & RBPMS2, OAZ2 \\
\hline & 14 & $55.45-55.55$ & 0.26 & - \\
\hline & 14 & $53.46-53.53$ & 0.26 & - \\
\hline & 15 & $42.78-42.86$ & 0.22 & AMPD3 \\
\hline & 15 & $29.48-29.65$ & 0.25 & UBE4A \\
\hline & 15 & $10.79-11.04$ & 0.24 & - \\
\hline & 16 & $24.11-24.35$ & 0.26 & IARS2, SLC30A10, EPRS, BPNT1, RAB3GAP2 \\
\hline & 17 & $59.04-59.2$ & 0.33 & SUDS3 \\
\hline & 21 & $27.49-30.62$ & 0.2 & - \\
\hline & 22 & $47.60-47.80$ & 0.15 & CACNA1D, CHDH, ACTR8 \\
\hline & 24 & $42.76-43.15$ & 0.22 & - \\
\hline & 29 & $20.02-20.15$ & 0.21 & LUZP2 \\
\hline \multirow{14}{*}{$\begin{array}{l}\text { Costeño con } \\
\text { Cuernos }\end{array}$} & 1 & $106.71-106.8$ & 0.25 & OTOL1 \\
\hline & 2 & $60.09-60.18$ & 0.2 & THSD7B \\
\hline & 3 & $19.57-19.66$ & 0.17 & JUN, MYSM1 \\
\hline & 3 & $109.46-109.54$ & 0.27 & - \\
\hline & 6 & $107.68-107.79$ & 0.25 & HTT \\
\hline & 7 & $21.55-21.61$ & 0.23 & CACTIN, TBXA2R, MFSD12, C19orf71 \\
\hline & 12 & $36.72-36.80$ & 0.33 & RNF17, PARP4, CENPJ \\
\hline & 12 & $2.32-2.46$ & 0.19 & DIAPH3 \\
\hline & 14 & $56.37-56.61$ & 0.2 & - \\
\hline & 15 & $59.75-60.03$ & 0.19 & - \\
\hline & 18 & $19.57-19.66$ & 0.17 & UQCRFS1, VSTM2B, VAC14, MTSS1L, IL34 \\
\hline & 21 & $109.46-109.54$ & 0.46 & HDGFRP3, TM6SF1, BTBD1, CTSH \\
\hline & 22 & $13.22-13.43$ & 0.18 & CACNA1A \\
\hline & 28 & $32.70-43.37$ & 0.19 & - \\
\hline
\end{tabular}

\section{DISCUSSION}

$\mathrm{AFC}$ and $\mathrm{CI}$ are complex traits that measure the reproductive efficiency in cattle herds (Rocha et al., 2012). In dairy cattle breeds, a reduced AFC has been associated with greater fertility and higher milk yield and it also has favorable genetic correlations with lifetime net merit, heifer conception rate, cow conception rate, and daughter pregnancy rate (Hutchison et al., 2017). Because of its complexity and the influence of several factors from the environment, a high heritability for these traits is not expected. This is corroborated by the low heritability values estimated in this study for both AFC and CI, which indicates an important influence of environmental factors on both traits. In general, the heritability $\left(h^{2}\right)$ described for these traits in the literature shows low to moderate values. In Colombian cattle Blanco orejinegro, Rocha et al. (2012) found a heritability of 0.15 and 0.13 for AFC and CI, respectively. A study made in Zebu cattle found heritabilities for CI ranging from 0.13 to 0.18 (Grossi et al., 2008). Given the higher $h^{2}$ value found for AFC in the present study, 
faster genetic progress would be expected in selecting ROMO and CCC animals for this trait compared to selection for CI. In dairy cattle, genomic tested young bulls had predicting transmitting abilities for AFC with reliabilities 20\% higher than parent averages (Hutchison et al., 2017), which shows the advantages of implementing genomic testing to improve selection for fertility traits.

For both breeds, candidate genes were found within or nearby to DNA sequences with a significant effect on CI and AFC. Two genomic regions in BTA22 that were associated with AFC, between 47.60-47.80 Mb in ROMO and between 13.22-13.43 Mb in CCC, contained o were close to genes coding for voltage-dependent calcium channels such as the calcium voltage-gated channel subunit alpha-1D gene (CACNA1D) and the calcium voltage-gated channel subunit alpha 1-A gene (CACNA1A). The first one is involved in the physiological mechanisms that are dependent on calcium, including the release of some hormones such as estrogens (Ji et al., 2016), whereas CACNA1A is involved in the formation of transmembrane ion channels that regulate selective permeability entry of calcium into the cells. This mechanism affects a variety of physiological processes dependent on calcium, mainly the release of hormones. Some SNPs in CACNAD1 and CACNA1A were found among the most explanatory polymorphisms for heifer conception rate and daughter pregnancy rate in dairy cows (Parker-Gaddis et al., 2016; Ortega et al., 2017). Daughter pregnancy rate is the lactating cow's interval of calving to conception, while heifer conception rate is the maiden heifer's ability to conceive and is defined as the percentage of inseminated heifers that become pregnant at each service, which is strongly related with AFC.

Furthermore, a region between 45.4 and $45.5 \mathrm{Mb}$ of BTA10 that contains the prostaglandin D2 (PGD2) receptor gene (PTGDR) was highly associated with AFC in ROMO. PGD2 is a signaling molecule involved in biological processes such as platelet aggregation, broncho-constriction and allergic diseases (Farhat et al., 2011), and it also plays an important role as a chemoattractant to recruit immune cells to the feto-maternal interface during pregnancy (Grabner et al., 2017). PGD2 also participates in the embryonic sex-determining male cascade and it seems to interfere with FSH action within granulosa, modulating the balance of proliferation, differentiation and steroidogenic activity of granulosa cells in humans (Farhat et al., 2011). There are other possible functions that have been found for PTGDR in relation to the fertility of other species. In dogs, an increased expression of PTGDR was observed by the presence of embryos during the pre-attachment phase (Grabner et al., 2017). In rabbits, Sosa-Madrid et al., (2018) reported a region in chromosome 17 containing PTGDR, which was highly associated to litter size traits such as total number born, number born alive and implanted embryos. The high association observed between a genomic region on BTA10 containing this gene and AFC in the present study, suggests that PTGDR might be essential in the pathways to embryo-maternal recognition in heifers.

In addition to this, the gene that codes for the progesterone receptor membrane component 2 (PGRMC2) was found within a region of BTA17 highly associated with CI in CCC. PGRMC2 is a progesterone (P4) receptor highly expressed in the bovine oviduct, particularly in the ampulla (Saint-Dizier et al., 2012). P4 is a hormone released from the corpus luteum that regulates the endometrial functions necessary to stimulate and maintain early embryonic growth, and facilitate implantation of the embryo (Lonergan, 2011). The levels of P4 and the expression of their receptors in the endometrial tissue plays an 
important role during pregnancy, as well as in the regulation of the different phases of the estrous cycle and the follicular growth in bovine females (Clark et al. al., 2016). These physiological mechanisms affect the postpartum resumption of ovarian cyclicity and the maintenance of pregnancy, which have a direct effect on $\mathrm{CI}$ in both heifers and cows

Another gene identified within a genomic region of BTA5 and associated with AFC in ROMO was synaptotagmin 10 (SYT10). This gene functions as a $\mathrm{Ca}(2+)$-sensor that triggers IGF-1 exocytosis in the secretory vesicles of the olfactory bulb neurons (Cao et al., 2011). The sense of olfaction plays an essential role in reproduction of cattle. For instance, besides the importance of this sense in processes of sexual attraction, estrus induction and reducing the postpartum anestrus, sexual development and maturity in young females is also influenced by olfaction through the perception of male pheromones (Padodara, 2014), then puberty and AFC of heifers could be accelerated by the presence of a bull. Additionally, Genomic association studies have found a relation between SYT10 and traits such as longevity (Mészáros et al., 2014) and stayability (Barreto et al., 2017) in dairy and dualpurpose cattle breeds. It is possible to hypothesize that given the influence of olfaction on reproduction and in turn the impact that the reproductive performance has on culling decisions, the polymorphisms and genes associated with fertility traits like AFC and CI might also have an effect on more complex traits such as longevity and stayability.

Other regions associated with AFC contained genes involved in physiological mechanisms that either directly or indirectly affect reproduction in both the female and male. Genes such as the mitochondrial isoleucine-tRNA synthetase gene (IARS2) and ring finger protein 17 (RNF17) were identified in genomic regions (BTA16 in ROMO and BTA12 in CCC) with a significant effect on AFC. IARS2 codes for proteins related to growth hormone deficiency (Moosa et al., 2017), while RNF17 codes for a protein that is expressed in mammal germinal cells and is essential for spermiogenesis and the development of the ovaries (Pan et al., 2005). The sexual maturity of heifers is directly related to the growth rate, therefore, it is possible that these genes participate in the regulation of biological mechanisms involved in growth, and in turn, affects the reproductive development of heifers to reach puberty. Furthermore, an additional couple of regions associated with AFC found in ROMO (BTA15) and CCC (BTA7) contained the ubiquitination factor E4A (UBE4A) and the CACTIN genes, both which code for proteins that intervene in the regulation of the immune system and possibly during early embryonic development. UBE4A is expressed in the ovarian tissue and might be involved in the development of the ovaries. However, UBE4A along with the glypican 5 gene (GPC5; highly associated with CI in CCC) have also been associated with the presence of pathological diseases such as serous cystadenocarcinoma in the female reproductive glands and the recessive disorder linked to the $\mathrm{X}$ chromosome characterized by accelerated pre and postnatal growth and the presence of supernumerary nipples (Alexander et al., 2011; Li et al., 2011; Baldwin et al., 2013).

Finally, it is important to note that in CCC, some genomic regions located in BTA1 and BTA14 showed a common effect for both AFC and CI. Likewise, a genomic region of BTA5 was also found significantly associated with both traits in ROMO. This would possibly suggest the presence of genes in these genomic regions with a pleiotropic effect on several traits that affect reproduction in cattle. Overall, the chromosomal regions identified in this study can be used to develop functional expression analyzes that allow the identification of genes, establishment of gene networks and confirmation of new 
polymorphisms that explain the inherent genetic variance of traits that measure reproductive performance in cattle. The polymorphisms with the most significant effect on AFC and CI might be considered for breeding selection strategies in order to improve these traits in beef and dairy cattle production systems.

\section{CONCLUSIONS}

A total of 66 significant associations between several SNPs genotyped using the BovineSNP50K_v2 and two fertility traits in Colombian cattle breeds were found. The most significant associations for CI were observed in BTA1, BTA3 and BTA14 and BTA1, while for AFC the highest associations were found on BTA1, BTA10 and BTA21 for AFC. Several genes were identified within or nearby to these SNP windows and might be involved in multiple physiological mechanisms that directly or indirectly affect reproductive performance in cattle. The annotated genes coding for important receptors such as CACNA1D, CACNA1A, PTGDR and PGRMC2, might play an important role in hormonal regulation, ovarian cyclicity and the pathways to embryo-maternal recognition and maintenance of pregnancy, affecting the AFC of heifers. Other interesting genes such as SYT10, IARS2, RNF17, UBE4A, CACTIN and GPC5 could be involved in biological processes that affect growth rate, gametogenesis, acceleration of puberty, regulation of immune system and early embryonic development, which would have a substantial effect on both AFC and CI. Genes with a pleiotropic effect on reproductive traits of CCC and ROMO cattle might be located on BTA1, BTA5 and BTA14.

\section{ACKNOWLEDGMENTS}

The authors acknowledge the funding received from the Ministerio de Agricultura y Desarrollo Rural of Colombia (MADR) through the Instituto Colombiano Agropecuario (ICA) and the Corporación Colombiana de Investigación Agropecuaria (Agrosavia).

\section{REFERENCES}

Aguilar I, Misztal I, Johnson DL, Legarra A, et al. (2010). Hot topic: a unified approach to utilize phenotypic, full pedigree, and genomic information for genetic evaluation of Holstein final score. J. Dairy. Sci. 93: 743-752.

AnimalQTLdb (2017). AnimalQTLdb. http://www.animalgenome.org/cgi-bin/ QTLdb/index. Accessed 7 Dec 2017

Alexander W, Aponte T, Chacon JB, Bravo WC, et al. (2011). Serous papillary ovarian cystadenocarcinoma in an 16year-oldpatient, a case report. Gac. Med. Bol. 34(1): 43-46.

Baldwin KL, Dinh EM, Hart BM and Masson PH (2013). CACTIN is an essential nuclear protein in Arabidopsis and may be associated with the eukaryotic spliceosome. FEBS. Lett. 587: 873-879.

Barreto TD, Alves JG, Beraldo SD, Bermal R, et al. (2017). Genomic analysis of stayability in Nellore cattle. PLoS One. 12(6): e0179076.

Bovine HapMap Consortium (2009). Genome-wide survey of SNP variation uncovers the genetic structure of cattle breeds. Science. 324: 528-532.

Browning SR and Browning BL (2011). Haplotype phasing: existing methods and new developments. Nat. Rev. Genet. 12(10): 703-14.

Cao P, Maximov A and Südhof TC (2011). Activity-dependent IGF-1 exocytosis is controlled by the Ca(2+)-sensor synaptotagmin-10. Cell. 145: 300-11.

Clark N, Pru C, Yee S, Lydon J, et al. (2016). Conditional ablation of progesterone receptor membrane component 2 causes female premature reproductive senescence. Endocrinology. 158(3): 640-651.

Ensembl.org (2017). Ensembl.org. https://www.ensembl.org/index.html. Accessed 7 Dic 2017.

Farhat A, Philibert P, Sultan C, Poulat F, et al. (2011). Hematopoietic-Prostaglandin D2 synthase through PGD2 production is involved in the adult ovarian physiology. J. Ovarian Res. 4(3): 1-13.

GeneCards (2017). GenesCards Human Gene Database. In: Weizmann Inst. Sci. http://www.genecards.org/. Accessed 7 Dic 2017. 
Graubner FR, Gram A and Kautz E (2017). Uterine responses to early pre-attachment embryos in the domestic dog and comparisons with other domestic animal species. Biol. Reprod. 97(2): 197-216.

Grossi DA, Frizzas OG, Paz CCP, Bezerra LAF, et al. (2008). Genetic associations between accumulated productivity, and reproductive and growth traits in Nelore cattle. Livest. Sci. 117: 139-146.

Hutchison JL, VanRaden PM, Null DJ, Cole JB, et al. (2017). Genomic evaluation of age at first calving. J. Dairy Sci. 100: 6853-6861.

Ji Y, Han Z, Shao L and Zhao Y (2016). Ultrasound-targeted microbubble destruction of calcium channel subunit $\alpha$ 1D siRNA inhibits breast cancer via G protein-coupled receptor 30. Oncol. Rep. 36: 1886-92.

Li F, Shi W, Capurro M and Filmus J (2011). Glypican-5 stimulates rhabdomyosarcoma cell proliferation by activating Hedgehog signaling. J. Cell Biol. 192: 691-704.

Lonergan P (2011). Influence of progesterone on oocyte quality and embryo development in cows. Theriogenology. 76 : 1594-1601.

Madrid S, Santacreu B, Fontanesi M and Blasco L (2018). A genomic region on chromosome 17 has a major impact on litter size traits in rabbits. In: World Congress on Genetics Applied to Livestock Production. 11: 163.

Martínez R, Gallego J, Onofre G, Pérez J, et al. (2009) Evaluación de la variabilidad y potencial genético de poblaciones de bovinos criollos colombianos. AGRI. 44: 57-66.

Matukumalli LK, Lawley CT, Schnabel RD, Taylor JF, et al. (2009). Development and characterization of a high density SNP genotyping assay for cattle. PLoS One. 4(4): 1-13.

Mészáros G, Eaglen S, Waldmann P and Sölkner J (2014). A Genome Wide Association Study for Longevity in Cattle. Open J. Genet. 04(01): 46-55.

Misztal I, Aggrey SE and Muir WM (2013). Experiences with a single-step genome evaluation. Poult. Sci. 92: 2530-4.

Moosa S, Haagerup A, Gregersen PA, Petersen KK, et al. (2017). Confirmation of CAGSSS syndrome as a distinct entity in a Danish patient with a novel homozygous mutation in IARS2. Am. J. Med. Genet. A. 173: 1102-1108.

Nicolazzi EL, Biffani S, Biscarini F, Orozco P, et al. (2015). Software solutions for the livestock genomics SNP array revolution. Anim. Genet. 46: 343-353.

Ortega MS, Denicol AC and Cole JB (2017). Association of single nucleotide polymorphisms in candidate genes previously related to genetic variation in fertility with phenotypic measurements of reproductive function in Holstein cows. J. Dairy Sci. 100(5): 3725-3734.

Ossa G, Abuabara Y, Pérez JE and Martínez G (2011). El ganado criollo colombiano Costeño con Cuernos (CCC). Anim. Genet. Resources 48: 101-107

Ossa G, Hinestroza AD, Rodríguez MS and García SR (2013). Training, development and phenotypic characterization of productive and reproductive characters Romosinuano herd of gene bank Colombia. Corpoica Cienc. Tecnol. Agropecu. 14(2): 231-243.

Pan J, Goodheart M, Chuma S, Nakatsuji N, et al. (2005) RNF17, a component of the mammalian germ cell nuage, is essential for spermiogenesis. Development. 132: 4029-39.

Padodara R (2014). Olfactory Sense in Different Animal. Indian J. Vet. Sci. 2(1): 1-14.

Parker KL, Null DJ and Cole JB (2016). Explorations in genome-wide association studies and network analyses with dairy cattle fertility traits. J. Dairy Sci. 99(8): 6420-6435.

Purcell S, Neale B, Todd-Brown K, Thomas L, et al. (2007). PLINK: a tool set for whole-genome association and population-based linkage analyses. Am. J. Hum. Genet. 81(3): 559-75.

Rocha JF, Gallego JL, Vásquez RF, Pedraza JA, et al. (2012). Estimation of genetic parameters for age at first calving and calving interval in Blanco Orejinegro (BON) breed cattle populations in Colombia. Rev. Colomb. Cienc. Pecu. 25: $220-228$

Rolf MM, Taylor JF, Schnabel RD, McKay SD, et al. (2010). Impact of reduced marker set estimation of genomic relationship matrices on genomic selection for feed efficiency in Angus cattle. BMC Genet. 11: 24

Saint-Dizier M, Sandra O, Ployart S, Chebrout M, et al. (2012). Expression of nuclear progesterone receptor and progesterone receptor membrane components 1 and 2 in the oviduct of cyclic and pregnant cows during the postovulation period. Reprod. Biol. Endocrinol. 10: 76.

Sargolzaei M, Chesnais JP and Schenkel FS (2014). A new approach for efficient genotype imputation using information from relatives. BMC Genomics. 15: 478.

Snelling WM, Cushman RA, Keele JW, Maltecca C, et al. (2013). Breeding and genetics symposium: Networks and pathways to guide genomic selection. J. Anim. Sci. 91: 537-552.

UniProt (2017). UniProt. http://www.uniprot.org/. Accessed 7 Dic 2017.

VanRaden PM (2008). Efficient methods to compute genomic predictions. J. Dairy Sci. 91: 4414-4423.

Wang H, Misztal I, Aguilar I, Legarra A, et al. (2012). Genome-wide association mapping including phenotypes from relatives without genotypes. Genet. Res. 94: 73-83.

Wiggans GR, VanRaden PM, Bacheller LR, Tooker ME, et al. (2010). Selection and management of DNA markers for use in genomic evaluation. J. Dairy Sci. 93: 2287-2292.

ZiminA V, Delcher AL, Florea L, Kelley DR, et al. (2009). A whole-genome assembly of the domestic cow, Bostaurus. Genome Biol. 10: R42. 